\title{
El derecho de peticionar ante las autoridades y el amparo por mora como respuesta al silencio de la Administración
}

The right of petition to authorities and the amparo for mora as a response to the silence of the Administration

$O$ direito de peticionar perante as autoridades e a proteção de amparo para mora em resposta ao silêncio da Administração

Le droit de pétition des autorités et la protection du retard de paiement en réponse au silence de l'administration

响应政府的沉默, 向当局提出请愿的权利和对逾期付款的 保护。

Zarina E. Ross ${ }^{1}$ | Universidad de Buenos Aires, Argentina

Revista Derechos en Acción ISSN 2525-1678/ e-ISSN 2525-1686

Año 4/Nº 13, Primavera 2019 (21 septiembre a 20 diciembre), 134-153

DOI: https://doi.org/10.24215/25251678e334

ORCID: https://orcid.org/0000-0001-5313-1651

Recibido: 07/06/2019

Aprobado: 25/09/2019

Resumen: En el presente trabajo se analiza el instituto del amparo por mora como herramienta con la que cuenta el ciudadano frente al silencio de la Administración Pública cuando éste ha ejercido su derecho de peticionar ante las autoridades consagrado constitucional y convencionalmente. Así, concretamente se intenta trazar la evolución jurisprudencial en la Provincia de Tierra del Fuego con relación al instituto, haciendo

\footnotetext{
1 Abogada por la Facultad de Derecho de la Universidad de Buenos Aires, Magister en Derecho Administrativo por la Facultad de Derecho de la Universidad Austral, diploma de honor por promedio distinguido. Email: zarinaross@hotmail.com
} 
especial referencia quién debe soportar las costas en dicho proceso judicial.

Palabras claves: Derecho de peticionar. Silencio de la Administración Pública. Amparo por mora. Costas en el proceso.

Abstract: This paper analyzes the institute of amparo for mora as a tool available to citizens in the face of the silence of the Public Administration when they have exercised their right to petition the constitutionally and conventionally enshrined authorities. Thus, it is specifically attempted to trace the jurisprudential evolution in the Province of Tierra del Fuego in relation to the institute, making special reference to who should bear the costs in this judicial process.

Keywords: Right to petition. Silence of the Public Administration. Amparo for arrears. Costs in the process.

Resumo: No presente trabalho é analisado o instituto de amparo para mora como ferramenta que 0 cidadão tem quando ele enfrenta 0 silêncio da Administração Pública quando exercitou seu direito de petição perante as autoridades reconhecido constitucionalmente e convencionalmente. Assim, tentando especificamente rastrear a evolução jurisprudencial na Província de Tierra del Fuego em relação ao instituto, fazendo referência especial a quem deve suportar os custos do referido processo judicial.

Palavras-chave: Direito de petição. Silêncio da Administração Pública. Amparo para amora. Custos no processo

Résumé: Dans cet article, la procédure d'amparo pour retard est analysé comme un outil dont dispose le citoyen face au silence de l'administration publique lorsqu'il a exercé son droit de pétition -constitutionnellement et conventionnellement établi- face aux autorités.Ainsi, en essayant spécifiquement de retracer l'évolution jurisprudentielle dans la province de Tierra del Fuego par rapport à l'institut, en faisant une référence spéciale à qui doit supporter les frais de ladite procédure judiciaire.

Mot-clés: Droit de pétition. Silence de l'administration publique. Amparo pour mûre. Coûts dans le processus.

摘要: 在当前的工作中, 分析了宪法权利保护延期研究所, 作为公民 在政府按照宪法和常规建立的行使其请愿权时行使沉默权的一种 
工具。因此, 特别是试图追溯蒂埃拉 ·德 - 韦戈省与该研究所有关 的法学演变, 特别提及谁必须承担司法程序中的费用。

关键字: 请愿权。公共行政部门的沉默。黑莓Amparo。过程中的成本。

\section{Introducción}

Sabido es que la Administración Pública está compelida a dar respuesta a las peticiones que los habitantes realicen ante ella, y el motivo de aquello se encuentra en la consagración que la Constitución Nacional hace del derecho de peticionar ante las autoridades su el artículo 14, que también tiene respaldo convencional en tanto el artículo 24 de la Declaración Americana de Derechos y Deberes del Hombre reconoce el derecho a obtener una decisión fundada que considere los argumentos esgrimidos por parte del ciudadano.

A nivel local, en Tierra del Fuego, la Constitución también reconoce dicho derecho en el artículo 14 inciso 9, en tanto establece que las personas gozan del derecho "A peticionar ante las autoridades y obtener respuesta fehaciente, y acceder a la jurisdicción y a la defensa de sus derechos.".

Tampoco se puede dejar de vincular a dicho derecho con la buena administración, entendida ésta en su triple dimensión, en primer lugar, como principio general de aplicación a la Administración Pública y al Derecho Administrativo; en segundo lugar, como una obligación de toda Administración Pública que se deriva de la definición del Estado Social y Democrático de Derecho, especialmente de la denominada tarea promocional de los poderes públicos en la que consiste esencialmente la denominada cláusula del Estado social: crear las condiciones para que la libertad y la igualdad de la persona y de los grupos en que se integra sean reales y efectivas, removiendo los obstáculos que impidan su cumplimiento y facilitando la participación social; y por último desde la perspectiva de la persona, pues se trata de un genuino y auténtico derecho fundamental a 
una buena Administración Pública, del que se derivan, una serie de derechos concretos, derechos componentes que definen el estatuto del ciudadano en su relación con las Administraciones Públicas y que están dirigidos a subrayar la dignidad humana ${ }^{2}$.

No se puede dejar de destacar que la satisfacción de este derecho, por lo general, trae como consecuencia la satisfacción de otro, por ejemplo el caso de un ciudadano que requiere a la Administración el otorgamiento de una pensión por discapacidad, si bien con el requerimiento realizado, éste hace ejercicio de su derecho de peticionar ante las autoridades, detrás de subyace la satisfacción de otro, por ello en el marco del Estado Constitucional y Social de Derecho este derecho adquiere especial relevancia. Recordemos que la finalidad está puesta en el pleno desarrollo de los ciudadanos. El Dr. Rodríguez Arana Muñoz es muy preciso al señalar que el tránsito del Estado liberal de derecho al Estado social trajo consigo una nueva dimensión del papel y de la funcionalidad de los derechos fundamentales, los que se configuran como un conjunto de valores o fines directivos de la acción positiva de los poderes políticos, y la Administración Pública del Estado social debe orientarse hacia su realización efectiva, pues el Derecho Público y la propia Administración en su conjunto, encuentran su razón de ser constitucional en la promoción de los derechos fundamentales. De esa forma, el Estado Constitucional y Social debe fomentar el pleno desarrollo de los ciudadanos. El interés general es entendido como concepto inmediatamente relacionado con la realización de los derechos fundamentales, y con estos de la dignidad humana ${ }^{3}$.

No obstante, en muchas ocasiones, la respuesta de la Administración es tardía y en más de una oportunidad es el propio

2 "Carta Iberoamericana de los Derechos y Deberes del Ciudadano en Relación con la Administración Pública" Aprobada por el Consejo Directivo del CLAD en reunión presencialvirtual celebrada desde Caracas el 10 de octubre de 2013.

3 Cfr. Rodríguez arana- muñoz, Jaime, Principios de Ética Pública ¿Corrupción o Servicio?, Editorial Montecorvo, Madrid, 1993, 47-62. 
ciudadano quien debe arbitrar los medios que tiene a su alcance para obtener de aquella una respuesta, aun cuando se sabe que uno de los principios que rigen en el procedimiento administrativo es el de la impulsión de oficio de las actuaciones. Ello se convierte claramente en una vulneración de los derechos de los ciudadanos.

Frente al silencio, entre las herramientas con las que cuentan las personas para instar a la Administración a brindar una respuesta, se encuentra el instituto del amparo por mora, y siendo que aquel es un requerimiento que se realiza ante el juez, se ha generado una problemática respecto a la imposición de las costas cuando la Administración da su respuesta ante el juez al momento de contestar el informe circunstanciado, acompañando en esa instancia el acto administrativo que debió haber emitido previamente, generando con ello que la cuestión planteada ante la autoridad judicial devenga abstracta.

En el presente trabajo, se intentará trazar la evolución jurisprudencial local con relación a quién debe soportar las costas en el amparo por mora.

\section{El amparo por mora. Concepto y finalidad}

Se dijo entonces que el amparo por mora, considerado como una acción, es una herramienta con la que cuentan los ciudadanos a fin de compeler a la Administración a dar una respuesta ante un pedido previo realizado ante ésta.

Los Dres. Comadira y Escola nos enseñan que el amparo por mora es un procedimiento judicial de amparo, establecido a favor del administrado, ante el retardo de un funcionario u órgano administrativo, para dictaminar o resolver, aun en asuntos de mero trámite, cuando ha transcurrido un plazo fijado para expedir el dictamen o dictar la resolución o proveído que corresponda, o bien cuando, de no existir plazo, transcurra el tiempo que exceda de lo razonable sin que esos actos se emitan ${ }^{4}$.

4 Cfr. Comarida, Julio Rodolfo y Escola, Héctor Jorge, "Curso de Derecho Administrativo" T. II, Editorial Abeledo Perrot, Buenos Aires, 2013, 1436. 
Explicado así, mediante el requerimiento realizado ante la autoridad judicial, la Administración debe brindar su respuesta, independientemente de cuál sea ésta, es decir si es a favor o en contra del pedido realizado por el ciudadano, pues la Administración sólo debe expedirse frente a su morosidad, y sólo cuando ésta emita el acto administrativo, el ciudadano podrá instar el procedimiento de impugnación correspondiente en caso de considerarlo necesario.

Entonces, para que pueda proceder el amparo por mora deber existir previamente un pedido realizado por el ciudadano ante la Administración, y el plazo para dar respuesta debe encontrarse vencido, pues si no se encuentra vencido, la acción no prosperará5.

Sobre el instituto la Corte Suprema de Justicia de la Nación ha expresado: "El amparo por mora de la administración constituye una especial acción de amparo, cuyos presupuestos de fondo se encuentran contenidos en el art. 28 de la ley 19.549 y al que, por principio y como tal, corresponde conferírsele un trámite autónomo y separado del de otras actuaciones de indole judicial'‘.

Por su parte, el Superior Tribunal local ha reiterado que "La acción judicial sub-examine se encuentra expresamente receptada en el art. 48 de la Constitución de la Provincia y ha sido reglada por los arts. 161 y 162 de la ley de procedimiento administrativo $N^{\circ} 141$. "El amparo por mora de la Administración consiste en un pedido de pronto despacho de las actuaciones administrativas efectuado ante un juez" (ver Hutchinson, Tomás "Procedimiento Administrativo de la Provincia de Tierra del Fuego, Antártida e Islas del Atlántico Sur", Emprendimientos Fueguinos, Río Grande, 1997, pág. 363), y requiere, para su procedencia, la existencia de un trámite administrativo y mora por parte de la administración en darle respuesta.

5 STJ TDF, "Albarracin, Dalma Alicia c/ IPAUSS s/ Amparo por Mora”, Expte. № 3110/15, sentencia de fecha 29 de mayo de 2015. STJ TDF, "Araya, Miguel Ángel c/ IPAUSS s/ Amparo por Mora", Expte. № 3101/15, sentencia de fecha 29 de mayo de 2015.

6 CSJN Fallos: 323:2602. 
Por su particular configuración "La pretensión de amparo por mora es instrumental. Su objeto es que el tribunal imparta una orden judicial de pronto despacho a la Administración con el propósito de que ésta dé trámite a una etapa procedimental demorada o directamente se expida. La autoridad requerida cumple con el mandato judicial cuando, en relación con la petición administrativa del actor, se expide. Se desnaturalizaría la finalidad del ampao por mora si el juez, en ese marco procesal, dispusidera (sic) específica y concretamente el sentido en que la Administración debe proveer o decidir la cuestión en análisis. Sobre este punto se ha pronunciado reiteradamente la jurisprudencia" (Patricio Marcelo E. Sammartino, "Amparo y Administración”, Abeledo Perrot, Buenos Aires, Tomo I, pag. 697)"”.

\section{Recepción normativa en el ámbito local}

En el ámbito local, el instituto del amparo por mora tiene consagración constitucional en tanto el artículo 48 establece que "En los casos en que esta Constitución, una ley u otra norma impongan a un funcionario, repartición o ente público administrativo, un deber concreto a cumplir en un plazo determinado, toda persona afectada puede demandar su cumplimiento judicialmente y peticionar la ejecución inmediata de los actos que el funcionario, repartición o ente público administrativo se hubiera rebusado a cumplir. El juez, previa comprobación sumarísima de los bechos enunciados, de la obligación legal y del interés del reclamante, debe librar mandamiento judicial de pronto despacho en el plazo que prudencialmente establezca."

De esa forma, dicho artículo fue reglamentado por los artículos 161 y 162 de la Ley Provincial No 141, de procedimiento administrativo, estableciendo el primero de ellos lo siguiente: "El que fuere parte en un expediente administrativo podrá solicitar judicialmente se libre orden de pronto despacho. Dicha

7 STJ, “Rojas, Daniel Antonio c/Caja de Previsión Social de la Pcia. De Tierra del Fuego y otro s/amparo por mora", Expediente $N^{0} 3649 / 18$, sentencia de fecha 11/07/18. 
orden será procedente cuando la autoridad administrativa bubiere dejado vencer los plazos fijados y en caso de no existir éstos, si hubieren transcurrido cuarenta y cinco (45) dias sin emitir la resolución de mero trámite o de fondo que requiera el interesado. La petición tramitará conforme a lo normado en el artículo 48 de la Constitución Provincial."

Del artículo transcripto surge pues, que se trata de una acción en tanto se inicia con una demanda que contiene una pretensión a ser satisfecha por el demandado (en el caso, que la Administración brinde una respuesta), por ello llama la atención que el instituto haya sido incorporado en la Ley de Procedimientos y no en el Código Contencioso Administrativo local (Ley 133), más este criterio en cuanto entender al amparo por mora como una acción no era compartido por el Superior Tribunal de Justicia Provincial, como más adelante se verá (causa "Gangas").

Por su parte, para que se pueda interponer dicha acción debe haberse instado previamente un procedimiento administrativo (mediante el ejercicio del derecho de peticionar ante las autoridades), por ello la legitimación para pretender la acción, va a estar condicionada a ser parte de ese procedimiento administrativo, y, por otro lado, en aquél se deben haber vencido los plazos para que la Administración se expida, que va a depender de la reglamentación del procedimiento iniciado (en el caso de los recursos y los reclamos el plazo que la ley le otorga a la Administración es de treinta días, pero en caso que la norma no establezca uno específico, el artículo determina como máximo para dar cumplimiento al requerimiento el de cuarenta y cinco días).

En cuanto al trámite que se le debe imprimir al mismo, la constitución hace referencia a que "El juez, previa comprobación sumarísima de los hechos enunciados, de la obligación legal y del interés del reclamante, (...)", es decir que el tipo de proceso a aplicar es el sumarísimo, sin embargo, el Código Contencioso Administrativo Provincial (Ley 133), no contempla dicho proceso, motivo por el cual se debe recurrir al Código Procesal, Civil, Comercial, Laboral, Rural y Minero (Ley 147). 
Por otro lado, con relación al tribunal ante el cual corresponda interponer la acción, se deberá estar a la materia en tanto en virtud de aquella la legislación provincial determina diferentes competencias, así por ejemplo en el caso del empleo público, deberá tomar intervención el juzgado laboral de primera instancia.

Con relación a ello, el Superior Tribunal de Justicia de Tierra del Fuego, ha expresado: "La acción la deduce en su calidad de afiliado a la obra social administrada por el IPAUSS, ya que es agente de la municipalidad local, según informó a requerimiento del Cuerpo.

En virtud de lo expuesto y tal como aconteciera en el precedente citado, la materia en discusión reside en la presunta mora del IPAUSS en dar respuesta al reclamo efectuado por un empleado público en virtud de su relación laboral con el Estado Municipal.

Por ello, resulta de aplicación lo preceptuado por el art. $3^{\circ} \mathrm{del}$ CCA en cuanto establece que el Juzgado de Primera Instancia del Trabajo conocerá "en las demandas o reclamaciones de los agentes públicos (...) en todo lo relacionado con el contrato de empleo o función públicos" (el subrayado se introduce en este acto).'•

Por otro lado, en materia de daños y perjuicios, es decir, sobre responsabilidad del Estado, ha entendido: "En el "sub lite", la acción persigue que la demandada se pronuncie con relación al reclamo presentado por el actor el 10 de agosto de 2016, solicitando el pago de una suma en concepto de daños y perjuicios "a partir del ilegítimo modo de proceder de personal de la dirección de Tránsito del Municipio local" (ver capítulo II. Hechos, del escrito de fs. 24/26).

El amparista formaliza un reclamo pecuniario invocando la responsabilidad civil que le cabría a la Municipalidad local, como consecuencia de la actuación de una de sus dependencias.

8 STJ TDF, "Mascareña, Pedro c/ I.P.A.U.S.S. s/ Amparo por Mora de la Administración", Expte. $N^{0} 2696 / 13$, sentencia de fecha 23 de octubre de 2013. 
La naturaleza de la cuestión planteada, excede -entonces- la propia del derecho administrativo, con independencia de que se encuentre involucrada la Administración; es de carácter netamente pecuniaria y versa sobre la falta de respuesta a la solicitud de pago de la suma de dinero estimada en la presentación glosada a fs. 16/17. ${ }^{\text {} . ~}$

Fuera de aquellos casos, cuando la materia es propia del derecho administrativo, la competencia originaria corresponde al Superior Tribunal de Justicia de la Provincia, conforme lo establecen los artículos 157 inc. "4" de la CPTDF, 1, 4, y 5 del CCA ${ }^{10}$.

Ahora bien, en la práctica provincial, al momento de "bilateralizar" el proceso, el tribunal libra oficio a la Administración requiriendo las actuaciones administrativas vinculadas a la acción deducida como así también la remisión de un informe circunstanciado de lo actuado.

Así, cuando el tribunal libra el oficio y es recibido por la Administración, ésta puede informar que ya se ha expedido o que los plazos aún no se encuentran vencidos o bien que no lo ha hecho, en el último caso, se hará lugar a la acción de amparo por mora otorgándosele a la Administración un plazo para pronunciarse.

Sin embargo, cuando la Administración se ha expedido dando respuesta al interesado, el tribunal deberá verificar si aquella es de fecha anterior a la interposición de la acción judicial o posterior, pues puede darse el caso que la misma venga dada por el hecho de haber tomado conocimiento la Administración

9 STJ TDF, “Torino, Pablo Andrés c/ Municipalidad de la ciudad de Ushuaia s/ Amparo por Mora s/ Cuestión de Competencia", Expte. N ${ }^{0} 3426 / 16$ SD, sentencia de fecha 24 de febrero de 2017.

10 STJ TDF, "Morales Leiva, Marta Josefa c/ I.P.A.U.S.S. s/ Amparo por Mora s/ Cuestión de Competencia", Expte. № 2783/13, sentencia de fecha 11 de julio de 2013. STJ TDF, “Oddo, Roberto Gerardo c/ Provincia de Tierra del Fuego s/ Amparo por Mora s/ Cuestión de Competencia", Expte. N ${ }^{0} 3314 / 16$, sentencia de fecha 27 de abril de 2016. STJ TDF, “Baigorri, José Alberto c/ Caja de Previsión Social de la Provincia de Tierra del Fuego s/ Amparo por Mora s/ Cuestión de Competencia", Expte. N 3951/19, sentencia de fecha 12 de julio de 2019. 
del inicio de la acción de amparo por mora en tanto haber sido comunicada del oficio.

En el primer caso, es decir en caso que la Administración haya dado respuesta previamente a la notificación de la existencia del amparo por mora, el tribunal, simplemente no hará lugar a la pretensión del accionante; sin embargo, para el caso en que la Administración brinde su respuesta luego de haber sido anoticiada de la existencia del amparo por mora, la cuestión devendrá abstracta, pues así lo ha entendido nuestro Superior Tribunal en reiteradas oportunidades ${ }^{11}$.

La cuestión así planteada no reviste mayores inconvenientes, más el problema en nuestra provincia vino dado con relación a la imposición de las costas, cuando la cuestión debe declararse abstracta.

\section{Las costas en el proceso de amparo por mora y la problemática referente a su imposición cuando la cuestión se declara abstracta}

Las costas son las erogaciones o gastos que las partes deben realizar con motivo de la tramitación del proceso judicial, entre las que se pueden enumerar: la tasa de justicia, los honorarios de peritos y abogados, etc ${ }^{12}$.

Por su parte, el STJ en el precedente "Sequeira"13 ha definido las costas como "los gastos que tienen al proceso como causa inmediata y directa de su producción, y deben ser pagados por las partes que intervienen en él."

\footnotetext{
11 STJ TDF, "Bragulat, Marcela c/ IPAUSS s/ Amparo por Mora", Expte. № 2690/12, sentencia de fecha 25 de febrero de 2014. STJ TDF, “Erramuspe, Héctor Oscar c/ Municipalidad de Ushuaia s/ Amparo por Mora", Expte. N2 2552/11, sentencia de fecha de 11 de abril de 2012.

12 Cfr. Osado Viruel, Sebastián y Sánchez Caparoós Mariana, “Código Contencioso Administrativo de la Provincia de Tierra del Fuego Ley Provincial N 133", Revista Argentina del Régimen de la Administración Pública. Año XXXV, suplemento 419, pág. 202.

13 STJ, "Sequeira, Catalina Graciela c/ I.P.A.U.S.S. s/ Amparo por Mora de la Administración, Expediente N 1940/07, sentencia de fecha 05/02/2008.
} 
Ahora bien, en cuanto a quién corresponde soportar las costas del proceso, el Código Contencioso provincial ${ }^{14}$ recoge el mismo principio que el Código Procesal local, en tanto disponen que las costas deberán imponerse a la parte vencida en el juicio siendo ésta la pauta general, pero estableciéndose ciertas excepciones $^{15}$.

Nos enseñan los maestros Fassi y Yáñez, que el fundamento de dicho principio general reside en el hecho objetivo de la derrota, con prescindencia de la buena o mala fe con que la parte vencida pueda haber actuado durante la tramitación del proceso, dicho principio constituye la aplicación de una directriz axiológica, de sustancia procesal, en cuya virtud se puede impedir, en cuanto es posible, que la necesidad de servirse del proceso para la defensa del derecho se convierta en daño de quien se ve constreñido a accionar o a defenderse en juicio para pedir justicia. Imponer la responsabilidad sobre el perdidoso encuentra su justificación en la mera circunstancia de haber gestionado un proceso sin éxito, como asimismo en la correlativa necesidad de resguardar la integridad del derecho que la sentencia reconoce a la parte vencedora, pues los gastos efectuados se producirían en una disminución del derecho judicialmente declarado. Éstas no constituyen una sanción para el derrotado, sino un resarcimiento al ganador de los desembolsos

\footnotetext{
14 Ley 133, artículo 58: "La sentencia impondrá a la parte vencida en el juicio el deber de pagar todos los gastos de la contraria, aun cuando éste no lo hubiese solicitado". Ley 147. artículo 78.- Principio general. 78.1 La parte vencida en el juicio deberá pagar todos los gastos de la contraria, aun cuando ésta no lo hubiese solicitado.

15 Ley 133, artículo 59.- Además de los supuestos establecidos en el artículo 68, el Tribunal podrá eximir total o parcialmente de esta responsabilidad al litigante vencido, siempre que encontrase mérito para ello, expresándolo en su pronunciamiento, bajo pena de nulidad. En materia previsional y de empleo público, cuando la parte vencida fuere el administrado, el Tribunal le impondrá las costas sólo cuando hubiese sostenido su acción con temeridad, o hubiere incurrido en pluspetición inexcusable, en relación a la parte excedida. Ley 147, artículo 78. 78.2 Sin embargo, el Juez podrá eximir total o parcialmente de esta responsabilidad al litigante vencido, siempre que encontrare mérito para ello, expresándolo en su pronunciamiento, bajo pena de nulidad.
} 
efectuados para obtener el reconocimiento de su derecho en juicio $^{16}$. Dicha finalidad es necesario no perder de vista.

Por otro lado, la doctrina también se ha pronunciado expresando que la imposión de costas en el amparo por mora dependerá en función de considerar aplicables las disposiciones de la ley de amparo o en su caso, las del Código Procesal (o en el caso nuestro del Código Contencioso). Así, si bien la ley de amparo comienza estableciendo que las costas se imponen al vencido, también determina que si antes del plazo fijado para responder el informe del artículo $8^{\circ}$ la Administración cesa el acto u omisión que fundó el amparo, no habrá imposición de costas (art. 14) ${ }^{17}$.

En el segundo caso, es decir, si se considera aplicable el Código Procesal, se sostuvo entonces que aun cuando se dé el caso en que la Administración se expide durante el transcurso del plazo para responder el informe, de igual forma le cabría a aquella la imposición de costas, por haber obligado al particular a litigar para obtener ese resultado ${ }^{18}$.

Pero como se dijo al inicio del presente trabajo, lo que aquí interesa es verificar cuál es el criterio a nivel local sobre la imposición de costas en el caso que el amparo por mora, sobre todo cuando la cuestión deviene abstracta pues la Administración en el transcurso de la respuesta del informe, se expide con relación al procedimiento administrativo oportunamente iniciado por el ciudadano.

Así, hasta febrero de 2008, el Superior Tribunal Provincial sostenía: "Comentando el criterio según el cual deben imponerse las costas a la administración en el procedimiento de amparo por mora, nos dice Osvaldo Alfredo Gozaini: ?Sin embargo, este

\footnotetext{
16 Cfr. FasSI, Santiago C. y yÁÑEZ, César D., “Código Procesal Civil y Comercial Comentado, Anotado y Concordado" T.I, Editorial Astrea, Buenos Aires, 2005, pág. 411/412.

17 Cfr. Comarida, Julio Rodolfo y Escola, Héctor Jorge, "Curso de Derecho Administrativo" T. II, Editorial Abeledo Perrot, Buenos Aires, 2013, 1444.

18 Cfr. Comarida, Julio Rodolfo y Escola, Héctor Jorge, "Curso de Derecho Administrativo" T. II, Editorial Abeledo Perrot, Buenos Aires, 2013, 1445.
} 
pensamiento -que puede sostenerse como mayoritario- tiene fundadas reservas en base a que como resultado de una estricta aplicación del sistema legal, no cabe la imposición de costas por las siguientes razones: 1) no hay partes; 2) como obvia consecuencia, no hay vencidos; 3) la indole de la intervención del juez; 4) el carácter opcional del amparo por mora. Ello determina principalmente que, ante la inexistencia de un verdadero proceso contencioso, no existen ni partes ni vencidos, sino tan sólo informantes.? (Costas Procesales, autor citado, pág.337, Ediar, Buenos Aires, 1990).

"Nuestro sistema constitucional parece seguir la doctrina recién transcripta. Véase que, según la Constitución de la Provincia: El juez, previa comprobación sumarísima de los hechos enunciados, de la obligación legal y del interés del reclamante, debe librar mandamiento judicial de pronto despacho en el plazo que prudencialmente establezca.? (art. 48, última parte).

"No hay lugar a controversia alguna pues, de la economía del texto bajo análisis, el tribunal sólo examina la satisfacción de los presupuestos contenidos en la norma $y$, de verificarse aquéllos, dispone la orden de pronto despacho. Es claro que no hace falta la intervención de la administración en carácter de parte, en tanto sólo es necesaria la comprobación de los requisitos exigidos por el constituyente. De manera tal que, a los fines indicados, basta tener a la vista las actuaciones administrativas para emitir el pronunciamiento de que habla el art. 48 de la Constitución.

"Ello sentado juzgamos que, en el caso, deben distribuirse las costas en el orden causado por no haber, stricto sensu, parte vencida." $"$.

Así, a la luz de dicho criterio jurisprudencial, el amparo por mora no era considerado propiamente un proceso, y por lo

19 STJ TDF, “Gangas, María Nieves c/ I.P.A.U.S.S. s/ Amparo por Mora de la Administración", expediente N 1.543/02 de la Secretaría de Demandas Originarias, sentencia del 5 de diciembre de 2002. 
tanto no existían vencedores ni vencidos, razón por la cual, las costas se imponían por el orden causado.

Sin embargo, al poco tiempo, más concretamente en septiembre de 2008, el Superior hubo de revisar el criterio sostenido en el precedente "Gangas", en la causa "Ameri" ${ }^{20}$, señalándose: "En cuanto a las costas entiendo necesario una revisión del criterio ya fijado por este Tribunal en el precedente "Gangas, María Nieves c/I.P.A.U.S.S. s/ Amparo por Mora de la Administración", expediente $N^{o} 1.543 / 02$ de la Secretaría de Demandas Originarias, sentencia del 5 de diciembre de 2002, registrada en el $T^{\circ}$ XLI, F 122/123.".

De esa forma, en dicho pronunciamiento se sostuvo: "(..) la Sala I del Contencioso de la Ciudad Autónoma ha explicado que "...el informe que corresponde realizar a la demandada frente al requerimiento judicial efectuado en el amparo por mora constituye un verdadero acto de defensa $y$, por ello, en él podrá alegar y probar la inexistencia de demora o aportar fundamentos que tiendan a justificarla. Así, la pretendida unilateralidad del proceso no es tal, pues subyace en el amparo por mora un conflicto entre partes adversas que para su solución requiere la intervención de la jurisdicción.

Ésta dirime la controversia mediante un acto de imperio dictado al cabo de un proceso gobernado por el principio de bilateralidad o contradicción. Y si en virtud del ejercicio del derecho de defensa, la administración demuestra la ausencia de mora, podrá eximirse de costas pues habrá quedado comprobado que no dio causa a la promoción de la acción”.

Tales observaciones resultan aplicables al orden local, pues, al requerirse las actuaciones administrativas el ente demandado por mora tiene la oportunidad procesal de explicar y/o acreditar su ausencia. En consecuencia, las costas habrán de ser

20 STJ TDF, “Ameri, Néstor Jorge y Montes, Domingo c/ I.P.A.U.S.S. s/ Amparo por Mora de la Administración", Exp. 2101/08, sentencia de fecha 11 de septiembre de 2008, registro TOMO LXIV Fo 185. 
impuestas a la administración siempre que de las constancias de la causa surja que se encontraba en mora en oportunidad de interponerse la demanda. Ello así, por aplicación del principio objetivo de la derrota en juicio establecido como pauta general por el art. 58 del CCA.

Nótese que en el orden normativo vigente no se compadece la existencia de la garantía prevista en los arts. 48 de la CPTDF y 161 de la LPA, con la carga de afrontar los gastos necesarios para ejercerla cuando ba sido conculcada por la autoridad pública. En tales condiciones, y habiéndose corroborado la mora del IPAUSS, corresponde imponerle el pago de las costas. (...).

Dicha solución es la que mejor se adecua con los principios vigentes en el Estado Constitucional y Social de Derecho, donde, como se dijo previamente, el eje se encuentra en la persona humana, más concretamente en su dignidad y desarrollo y ello así en tanto la mora en que incurre la Administración cuando no da respuesta oportuna a un requerimiento realizado por un ciudadano, esperando a que éste deduzca su amparo por mora para obtener una respuesta de ella, es una omisión arbitraria e ilegal que lesiona el derecho a obtener un pronunciamiento expreso dentro de un plazo razonable, todo ello vinculado además con la garantía constitucional y convencional del debido proceso, en tanto que el derecho a peticionar no se agota en el mero acto de su ejercicio por parte del interesado, sino que exige una respuesta de la administración.

La omisión de la Administración en dar respuesta oportuna al ciudadano, implica también una violación a la tutela administrativa efectiva, receptada por la Corte Suprema de Justicia en el caso "Losicer" 21 , donde se dijo: "La irrazonable dilación del procedimiento administrativo resulta incompatible con el derecho al debido proceso amparado por el artículo 18 de la Constitución Nacional y por el artículo 8 de la Convención Americana

21 CSJN, “Losicer, Jorge Alberto y otros c/ BCRA - Resol.169/05", 26/06/2012. 
sobre Derechos Humanos ("CADH"). Las citadas garantías resultan aplicables al procedimiento administrativo incoado por el Banco Central de la República Argentina ("BCRA"), aun cuando las sanciones aplicadas por el mismo hayan sido calificadas por la jurisprudencia de la CSJN como de carácter disciplinario y no penal ("Fallos": 275:265; 281:211; entre otros). La garantía constitucional de la defensa en juicio incluye el derecho de todo imputado obtener un pronunciamiento que, definiendo su posición frente la ley la sociedad, ponga término del modo más rápido posible, la situación de incertidumbre de innegable restricción que comporta el enjuiciamiento penal. El "plazo razonable" de duración del proceso constituye, entonces, una garantía exigible en toda clase de proceso, difiriéndose los jueces la casuística determinación de si se ha configurado un retardo injustificado de la decisión."

Luego, concretamente con relación al "plazo razonable", la Corte Federal hubo de explayarse en la causa "Bonder Aaron" ${ }^{22}$, donde se dijo: "El "plazo razonable" de duración del proceso al que se alude en el inciso 1, del art. 8, constituye, entonces, una garantía exigible en toda clase de proceso, difiriéndose a los jueces la casuística determinación de si se ba configurado un retardo injustificado de la decisión. Para ello, ante la ausencia de pautas temporales indicativas de esta duración razonable, tanto la Corte Interamericana - cuya jurisprudencia puede servir de guía para la interpretación de los preceptos convencionales (Fallos: 318: 514; 323: 4130, entre otros)- como el Tribunal Europeo de Derechos Humanos -al expedirse sobre el punto 6.1 de la Convención Europea para la Protección de los Derechos Humanos y Libertades Fundamentales que contiene una previsión similar- han expuesto en diversos pronunciamientos ciertas pautas para su determinación y que pueden resumirse en: a) la complejidad del asunto; b) la actividad procesal del interesado; c) la conducta de las autoridades judiciales $y$

22 CSJN, "Bonder Aaron (Emperador Compañía Financiera S.A.) y otros c/ B.C.R.A. s/ resol. 178/93", sentencia 19 de noviembre de 2013. 
d) el análisis global del procedimiento (casos "Genie Lacayo vs. Nicaragua", fallada el 29 de enero de 1997, párrafo 77 y "López Álvarez v. Honduras", fallado ello de febrero de 2006; "Kbnig", fallado el 10 de marzo de 1980 y publicado en el Boletín de Jurisprudencia Constitucional 1959-1983 en Madrid por las Cortes Generales)."

Siendo así, si recae sobre la Administración la obligación de expedirse frente al ejercicio del derecho de peticionar ante las autoridades que tienen los ciudadanos y considerando que la tutela administrativa efectiva es un derecho que también se reconoce convencionalmente, y aquella implica que la Administración debe expedirse en un "plazo razonable" a fin de no vulnerar garantías constitucionales, luego, si es el propio ciudadano quien debe instar a la autoridad pública para que ésta brinde una respuesta, no resulta coherente que las costas sean impuestas por el orden causado, pues es precisamente la Administración quien no cumple con sus obligaciones cuando no se expide dentro del plazo legal.

El criterio fijado en la causa "Ameri", fue luego moderado por el propio Superior Tribunal en la causa "Miño"23, al considerar que cuando la cuestión se declara abstracta por haberse emitido el acto cuya mora se imputaba a la Administración, la distribución de costas por su orden o a cargo de ésta, depende de las circunstancias particulares del proceso, correspondiendo valorar -en cada caso- la diligencia puesta en el obrar del peticionante durante el trámite administrativo, así como las causales de justificación de la tardanza alegadas por la Administración al responder el traslado de la acción, textualmente expresó: "Quiere decir entonces que cuando se declaró la cuestión abstracta, por haberse dictado el acto cuya mora se imputaba a la administración, las costas fueron distribuidas por su orden cuando el propio peticionante no ba obrado diligentemente en

23 STJ TDF, “Miño, Miriam Liliana c/ Municipalidad de Ushuaia s/ Amparo por Mora s/Recurso de Queja", Expte N 1.252/09 STJ SR, sentencia de fecha 15 de abril de 2010, registrada en $\mathrm{T} X \mathrm{VI}-\mathrm{F}^{0} 302 / 309$. 
el trámite seguido ante la administración, o bien cuando esta última explica adecuadamente su tardanza."

Es decir, que cuando corresponde declarar abstracto el amparo por mora en virtud de haberse expedido la Administración respecto del procedimiento en el que se encontraba en mora, deberá estarse a la conducta desplegada por el peticionante durante el trámite administrativo, como así también a las causales de justificación de la tardanza alegadas por la Administración al responder el traslado de la acción. De esa forma, el criterio sustentado en "Ameri", es moderado en tanto se deberá analizar caso por caso, debiéndose atender a las particularidades de cada uno, circunstancia que resulta razonable, pues puede darse el caso que la demora en que incurre la Administración sea a causa del proceder del ciudadano (aunque el caso sea el menos habitual).

La doctrina así expuesta fue la aplicada constantemente tanto por el Superior Tribunal de Justicia como por los tribunales inferiores, más durante el transcurso del 2019, en una causa que devino abstracta, el Superior se ha expresado nuevamente con relación a la imposición de las costas imponiéndolas por el orden causado, por aplicación del art. 59 del Código Contencioso. ${ }^{24}$

No obstante, ha de considerarse que siendo la doctrina que surge de "Ameri" y "Miño" la que mejor se adecua a los principios vigentes en el Estado Constitucional de Derecho como se indicó previamente, un cambio jurisprudencial debería estar motivado explicando las razones de aquel.

\section{Conclusiones}

A modo de conclusión se puede decir entonces que el instituto del amparo por mora es considerado en la actualidad

\footnotetext{
24 STJ TDF- "Avellaneda, Raúl Ramón A. c/ Gobierno de la Pcia. de Tierra del Fuego AelAS (Ministerio de Gobierno y Justicia) s/ Amparo por Mora", expediente № 3789/18, sentencia del 20 de agosto de 2019 .
} 
como una acción con la que cuentan los ciudadanos cuando la Administración vulnera el derecho de peticionar ante las autoridades en tanto no brinda una respuesta en tiempo oportuno, y supone la existencia de un procedimiento administrativo y el vencimiento de un plazo legal.

Así, y toda vez que recae sobre la Administración la obligación de expedirse, resulta acertado que, si ésta no lo hace en el plazo legalmente establecido, las costas recaigan en aquella, pues es quien ha obligado al ciudadano a instar tal acción, y ello, como se dijo, encuentra su justificación en el hecho de haber gestionado un proceso en el cual finalmente el tribunal ordena que ésta se pronuncie respecto del procedimiento administrativo iniciado por el ciudadano, y lo mismo ocurre en el caso que finalmente la Administración dé su respuesta al momento de contestar el informe circunstanciado, pues en la mayoría de los casos, la respuesta brindada, precisamente tiene su razón de ser en el hecho de haber sido comunicada de la existencia del amparo por mora. Es decir, que, si bien la cuestión devendría abstracta, el ciudadano tuvo que acudir al tribunal para poder satisfacer su requerimiento ante la Administración. La imposición de costas a la Administración, aun cuando la cuestión deviene abstracta resguarda la integridad del derecho de peticionar ante las autoridades, pues los gastos en los que el ciudadano incurrió para obtener dicho pronunciamiento, producirían una disminución de dicho derecho. 